\title{
Defect Classification in Fabric Web Material using LabVIEW
}

\author{
G.Revathy \\ PG Scholar, \\ Dept. of Electronics and Instrumentation \\ Engineering, Kongu Engineering College, \\ Perundurai, Erode-638052, Tamilnadu, India.
}

\author{
P.Vidhyalakshmi \\ Assistant Professor(SRG), \\ Dept. of Electronics and Instrumentation \\ Engineering, Kongu Engineering College, \\ Perundurai, Erode-638052, Tamilnadu, India.
}

\begin{abstract}
Textile manufacturing is a major industry in India. It is based on the conversion of three types of fibre into yarn which in turn is woven into fabrics. Fabrics are textile materials which are made through weaving, knitting, braiding and bonding of fibres. Weaving is described as inter-lacing of two distinct set of threads to form cloth, rug or other type of woven textile. The lengthways threads are known as the warp and the crossway threads are known as the weft.Quality plays a vital role in fabric manufacturing. The success of a weaving mill is significantly highlighted by its success in reducing fabric defects.Fabric inspection in offline is performed manually by skilled staff with a maximum accuracy of only $60 \%-75 \%$. Automated fabric inspection would seem to offer a number of potential advantages, including improved safety, reduced labour costs, and the elimination of human error. Therefore, automated visual inspection is gaining increasing importance in weaving industry.

This project proposes a automated fabric inspection system with benefits of low cost and high detection rate. Four types of faults are considered for analysis. Both normal and faulty images are processed and features are extracted using Gray Level Co-occurrence Matrix (GLCM).Further fuzzy rule based classsification is done.
\end{abstract}

\section{Keywords}

Fabric Inspection ,Defect Identification, Feature Extraction, Fuzzy if-then rules, Classification.

\section{INTRODUCTION}

The textile industry plays a vital role in Indian economy.The modern weaving Industry faces a lot of difficult challenges to create a high productivity as well as high-quality-manufacturing environment [3]. Because production speeds are faster than ever and because of the increase in roll sizes, manufacturers must be able to identify defects, locate their sources, and make the necessary corrections in less time so as to reduce the amount of second quality fabric. This in turn places a greater strain on the inspection departments of the manufacturers. Due to factors such as tiredness, boredom and, inattentiveness, the staff performance is often unreliable. The inspector can hardly determine the level of faults that is acceptable, but comparing such a level between several inspectors is almost impossible [7]. Therefore, the best possibility of objective and consistent evaluation is through the application of an automated inspection system.

\section{FABRIC DEFECTS}

A fabric is a flat structure consisting of fibrous materials, either natural or man- made. The fabric defect could be simply defined as an abnormality in or on the fabric construction. The woven fabric which is a finished product of many accumulated manufacturing processes shows various kinds of defects. Therefore, the source of the fabric defect has a vital importance to differentiate between and/or explain these defects. When yarn is woven on the loom, most of the defects occurs. Some minor fabric defects may be rectified during weaving whereas major defects are rectified after weaving. The common fabric defects are further explained.

Missing Yarn - It is caused by one end of yarn missing from feed and machine continuing to run. It is of two types, namely vertical and horizontal.

Hole - A fabric area free of both of warp and weft threads. It is a mechanical fault caused by a broken machine part, high tension on yarn. It is major fabric defect.
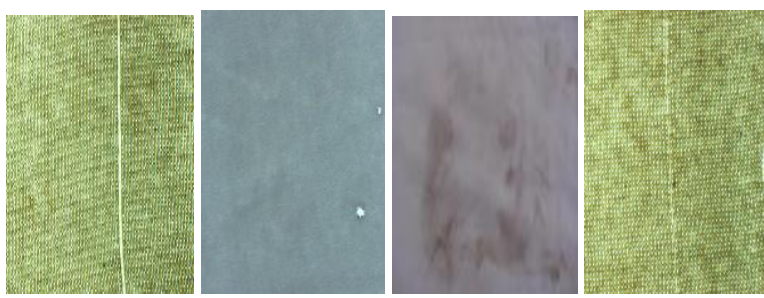

Figure 1 Web Material with Missing Yarn, Hole, Oil Spot and Needle Line

Oil Spot - It is caused by too much oiling on loom parts or from other external source. Oil spot may be major or minor defect. Oil spots in fabrics can be removed by scouring process.

Needle line: Needle Line is caused by bent needle forming distorted stitches in a vertical line. It may be major or minor fabric defect.

\section{IMPORTANCE OF THE AUTOMATED INSPECTION METHOD}

The inspection process relies strictly on the human eye and is done after the fabric manufacturing process. Human inspection consists of many drawbacks. It is a time consuming process, requires skilled and efficient labours and it is extremely difficult to achieve $100 \%$ fabric inspection with this traditional method [5]. In order to overcome these drawbacks an automated inspection system was proposed. 
An automated inspection system usually consists of a computer-based vision system. Because they are computerbased, these systems do not suffer the drawbacks of human visual inspection. Automated systems are able to inspect fabric in a continuous manner without pause. Automated system are reliable, reproducible and free from the subjective deficiencies of the manual fabric inspection. The system can increase the efficiency of production lines and improve quality of product well. A good system means lower labour cost and shorter production time.

In India, textile manufacturing plays an important role and traditional method is followed. The cost of automated system seems to be high as these machines are imported from other countries. The small scale industries are not in a position to offer these high cost. In order to overcome this our system was proposed with low cost and high quality.

The proposed system will be of low cost with inspection. It is capable of identifying all defects. Because the defect-free fabric has a periodic regular structure. So the occurrence of a defect in the fabric will break the regular structure. Hence, the fabric defects can be detected by monitoring fabric structure.

\section{PROPOSED TECHNIQUE}

The purpose of this project is to fully inspect the fabric during weaving process in the textile industry. Digital images of fabric products are obtained using a Standard High resolution CCD Camera. The captured image is considered for preprocessing and then it is subjected to wavelet transform. Five different Gray Level Co-occurrence Matrices (GLCM) are calculated for the preprocessed, transformed image and statistical features are extracted from each matrix.

The proposed scheme will provide high defect detection success rate as statistical and spectral approach are combined. Three major steps are involved in defect detection. The first step is to preprocess the input image .The second is to take wavelet transform for the preprocessed image. The third is to formulate GLCM for the transformed image. In the proposed scheme, the input image obtained from frame grabber is preprocessed and analyzed for fault detection. During preprocessing, the fabric image is histogram equalized and then converted into wavelet transformed image, so that the resultant image will have the defect in an enhanced form. Thus the resultant image will be more suitable with distinct defect for detection.

The gray level co-occurrence matrix, is one of the most popular statistical texture analysis tools for fabric defect detection. The principle is based on repeated occurrences of different gray level configurations in a texture. The gray level co-occurrence matrix contains information about the positions of pixels having similar gray level values. The second order statistics approximate the probability distribution function of the given texture .

To do that, it is accumulated into a set of 2D matrices, each of which measures the spatial dependency of two graylevels, given a displacement vector.The block diagram of proposed methodology of fabric defect detection is illustrated in the following figure 2 .

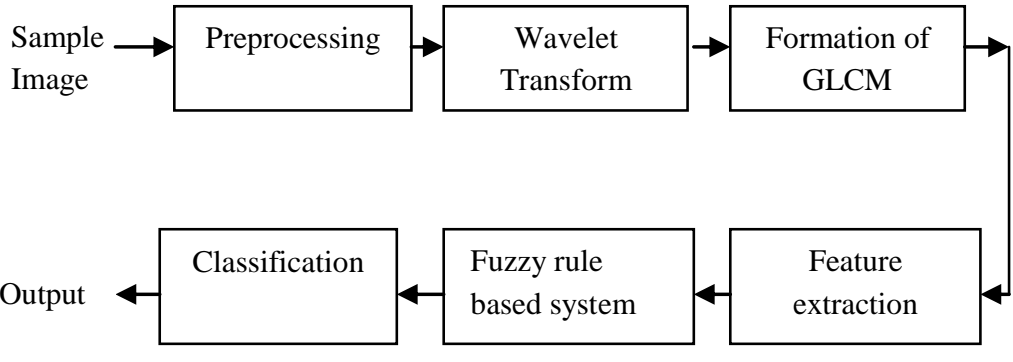

Figure 2 Block diagram for proposed methodology

\subsection{Preprocessing}

Pre-processing is done to enhance recognition performance in the presence of illumination variations, pose/expression/scale variations and resolution enhancement. The input image is obtained from the frame grabber. Isolation of minor fault is difficult as the image obtained from frame grabber is of smaller size. In order to overcome this, the image has to be preprocessed. Preprocessing involves Histogram Equalization.

\subsubsection{Histogram Equalization}

The input image is subjected to histogram equalization to enhance the quality of image .Histogram Equalization is applied to assign the intensity values of pixel in the input image such that the output image contains uniform distribution of gray values. The result is displayed below in figure 3 .
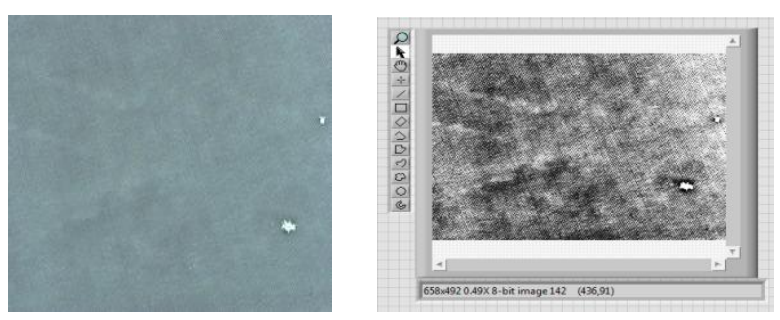

Figure 3 Preprocessing

\subsection{Wavelet Transformation}

The preprocessed image is subjected to wavelet transform. The transformed image will provide more accurate result [6]. A two dimensional digital image can be represented by a 2-D array $X[a, b]$ with a rows and $b$ columns, where $a, b$ are positive integers. Row-wise and column wise operations are performed to get DWT coefficients LL,HL,LH,HH. They are called sub-bands. The LL sub-band can be further decomposed into four sub-bands by following the above procedure. This process can continue to the required number of levels. This process is called multi level decomposition [12]. The wavelets are chosen based on their shape and their ability to analyze the signal in a particular application. Discrete wavelet Transform was performed. In DWT four bands are available. High pass and low pass filters are used to decompose the image first row-wise and then column wise. The transformed image is shown in the following figure 4 


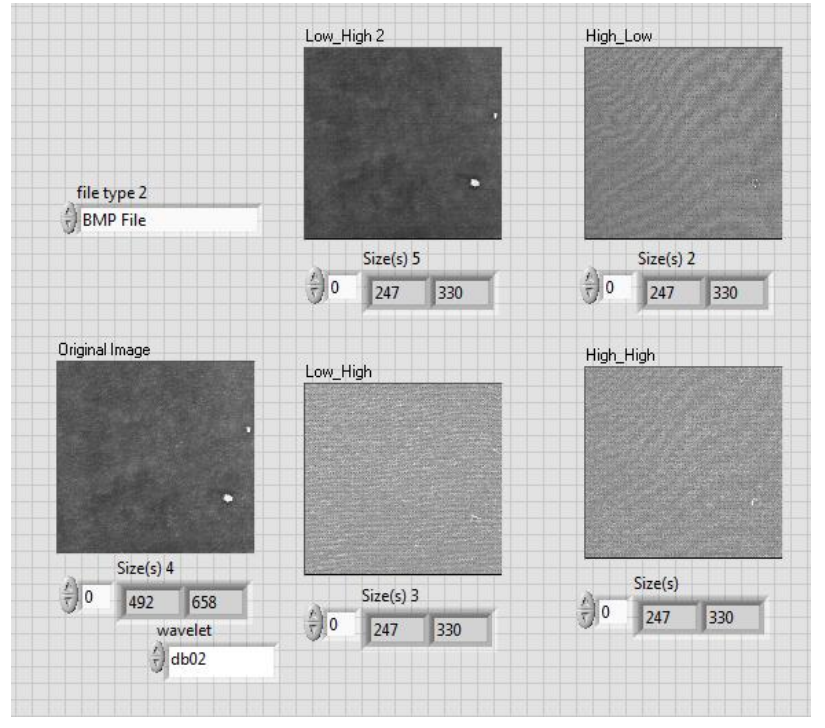

Figure 4 Wavelet Transform of the image

\subsection{Feature Extraction Using GLCM}

The co-occurrence matrix is one of the most popular statistical texture analysis tools for fabric defect detection . It is known also as the spatial gray-level dependence. The principle is based on repeated occurrences of different grey level configurations in a texture. The co-occurrence matrix contains information about the positions of pixels having similar gray level values. These second order statistics approximate the probability distribution function of the given texture. To do that, it is accumulated into a set of 2D matrices, each of which measures the spatial dependency of two gray-levels, given a displacement vector.. Zero orientation is considered here for extracting the textural features. The input image after preprocessing and wavelet transform is taken for feature extraction by using GLCM technique. 12 features are extracted to identify and classify the faults. The extracted features are Autocorrelation, Contrast, Cluster Shade, Dissimilarity, Energy, Entropy, Homogeneity, Sum average, Inverse Different Moment, Sum of squares, Correlation and Cluster Prominence.

\subsection{Fuzzy Logic System}

Fuzzy logic is much more general than traditional logical systems. The greater generality of fuzzy logic is needed to deal with complex problems in the realms of search, question-answering decision and control[1]. Fuzzy logic provides a foundation for the development of new tools for dealing with natural languages and knowledge representation. A fuzzy expert system is an expert system that uses a collection of fuzzy membership functions and rules, instead of Boolean logic, to reason about data[4]. The set of rules in a fuzzy expert system is known as the rule base or knowledge base. Fuzzy Logic system consists of three steps namely fuzzification, fuzzy inference method, defuzzification. The block diagram of the fuzzy logic system is shown in figure 5 .

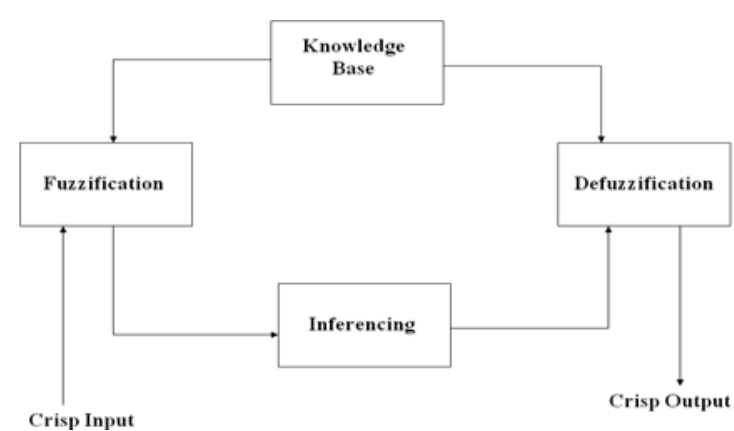

Figure 5 Fuzzy Logic System

The general inference process proceeds in three (or four) steps.

1. In FUZZIFICATION, the crisp values are transformed into grades of membership for(linguistic terms)fuzzy sets. The membership function is used to relate the grade to each linguistic terms. The crisp input values are tabulated in the below table.

Table 1 Crisp Input Variables

\begin{tabular}{|c|c|c|}
\hline S.No & Input Variables & Range \\
\hline 1 & Contrast & $0-0.8$ \\
\hline 2 & Auto Correlation & $20-35$ \\
\hline 3 & Sum Average & $10-18$ \\
\hline 4 & Sum of Squares & $8-20$ \\
\hline 5 & Cluster shade & $-15-0$ \\
\hline 6 & Cluster prominence & $150-300$ \\
\hline 7 & Dissimilarity & $0-0.6$ \\
\hline 8 & Energy & $0-0.16$ \\
\hline 9 & Entropy & $2.5-4$ \\
\hline 10 & Homogeneity & $0.5-1$ \\
\hline
\end{tabular}

2. In INFERENCE, the truth value for the premise of each rule is computed, and applied to the conclusion part of each rule. This results in one fuzzy subset to be assigned to each output variable for each rule. Usually only MIN or PRODUCT are used as inference rules. In MIN inferencing, the output membership function is clipped off at a height corresponding to the rule premise's computed degree of truth (fuzzy logic AND). In PRODUCT inferencing, the output membership function is scaled by the rule premise's computed degree of truth. The membership values are tabulated in the below table.

Table 2 Membership Values

\begin{tabular}{|l|l|c|c|c|}
\hline \multirow{2}{*}{ S.No } & \multirow{2}{*}{ Input Variables } & \multicolumn{3}{|c|}{ Membership Values } \\
\cline { 3 - 5 } & & Low & Medium & High \\
\hline 1 & Contrast & $0-0.4$ & $0.4-0.6$ & $0.6-0.8$ \\
\hline 2 & Auto Correlation & $20-25$ & $25-30$ & $30-35$ \\
\hline 3 & Sum Average & $10-13$ & $13-15$ & $15-18$ \\
\hline 4 & Sum of Squares & $8-12$ & $12-16$ & $16-20$ \\
\hline 5 & Cluster shade & $-15-10$ & $-10-5$ & $-5-0$ \\
\hline 6 & $\begin{array}{l}\text { Cluster } \\
\text { prominence }\end{array}$ & $150-200$ & $200-250$ & $250-300$ \\
\hline 7 & Dissimilarity & $0-0.2$ & $0.2-0.4$ & $0.4-0.6$ \\
\hline 8 & Energy & $0-0.06$ & $0.06-0.12$ & $0.12-0.16$ \\
\hline 9 & Entropy & $2.5-3$ & $3-3.5$ & $3.5-4$ \\
\hline 10 & Homogeneity & $0.0-0.5$ & $0.5-0.75$ & $0.75-1$ \\
\hline
\end{tabular}


3. In COMPOSITION, all of the fuzzy subsets assigned to each output variable are combined together to form a single fuzzy subset for each output variable. Again, usually MAX or SUM are used. In MAX composition, the combined output fuzzy subset is constructed by taking the point wise maximum over all of the fuzzy subsets assigned to variable by the inference rule (fuzzy logic OR). In SUM composition, the combined output fuzzy subset is constructed by taking the point wise sum over all of the fuzzy subsets assigned to the output variable by the inference rule.

4. DEFUZZIFICATION is used to convert the fuzzy output set to a crisp number. There are different types of defuzzification methods are available. The most common methods are the CENTROID and MAXIMUM methods. In the CENTROID method, the crisp value of the output variable is computed by finding the variable value of the center of gravity of the membership function for the fuzzy value. In the MAXIMUM method, one of the variable values at which the fuzzy subset has its maximum truth value is chosen as the crisp value for the output variable. The output variables are tabulated in the below table.

Table 3 Output Variables

\begin{tabular}{|l|l|c|}
\hline S.No & Output Variables & Output Range \\
\hline 1 & No Defect & $0-1$ \\
\hline 2 & Hole & $0.6-2$ \\
\hline 3 & Missing Yarn & $1.5-3$ \\
\hline 4 & Oil Spot & $2.5-4$ \\
\hline 5 & Needle Drop & $4.2-5$ \\
\hline
\end{tabular}

\section{RESULTS AND DISCUSSIONS}

\subsection{Defect Identification}

For validating the result for the proposed method, 50 fabric samples are considered, in which 30 are defect fabric samples. The proposed Fuzzy rule based method produces better result. Table 4 shows the defect identification results for the proposed method.

Table 4 Defect Identification Results

\begin{tabular}{|l|c|c|c|}
\hline $\begin{array}{l}\text { Inspection } \\
\text { Method }\end{array}$ & $\begin{array}{l}\text { No.of } \\
\text { samples }\end{array}$ & $\begin{array}{l}\text { No of } \\
\text { defect } \\
\text { images }\end{array}$ & $\begin{array}{l}\text { No of } \\
\text { defect } \\
\text { identified }\end{array}$ \\
\hline $\begin{array}{l}\text { Fuzzy } \\
\text { Rule } \\
\text { Based } \\
\text { Method }\end{array}$ & 50 & 40 & 39 \\
\hline
\end{tabular}

\subsection{Defect Classification}

In defect classification, when less no of features are considered the accuracy of classification is less. When more number of features are considered the accuracy of classification is best. Front panel diagram for defect classification is shown in figure 6 .

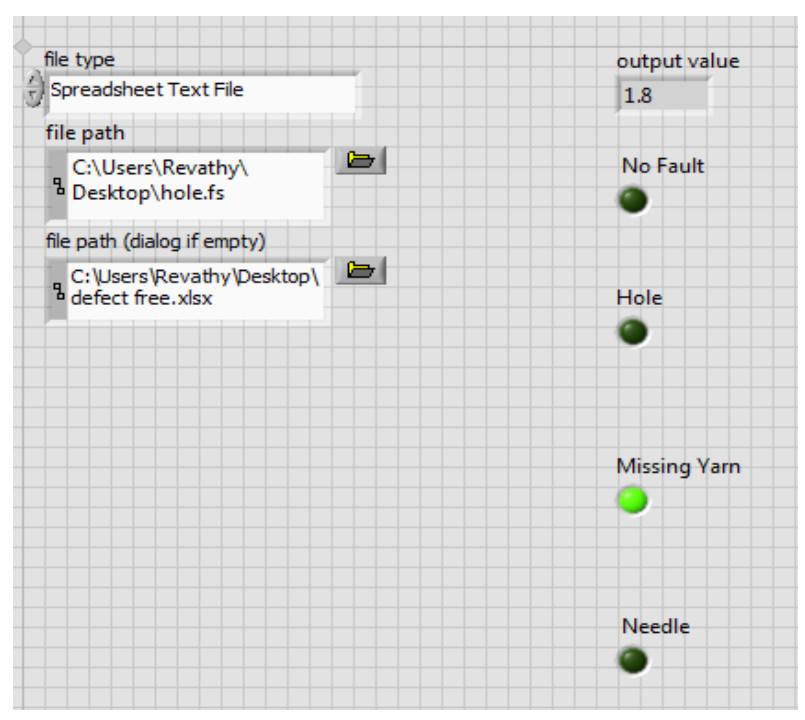

Figure 6 Defect Classification

Table 5 shows the classification result of the proposed method with different no of features considered.

Table 5 Classification Results

\begin{tabular}{|l|l|l|l|l|l|}
\hline \multicolumn{2}{|l|}{$\begin{array}{l}\text { Inspection } \\
\text { Method }\end{array}$} & $\begin{array}{l}\text { No of } \\
\text { Sample } \\
\text { Images }\end{array}$ & $\begin{array}{l}\text { No of } \\
\text { defect } \\
\text { images }\end{array}$ & $\begin{array}{l}\text { No of } \\
\text { images } \\
\text { identified }\end{array}$ & $\begin{array}{l}\text { No of } \\
\text { images } \\
\text { classified }\end{array}$ \\
\hline $\begin{array}{l}\text { Fuzzy } \\
\text { Rule } \\
\text { Based } \\
\text { Method }\end{array}$ & $\begin{array}{l}\text { 5 features } \\
\text { considered }\end{array}$ & 50 & 40 & 39 & 35 \\
\cline { 2 - 6 } & $\begin{array}{l}\mathbf{1 0} \\
\text { features } \\
\text { considered }\end{array}$ & 50 & 40 & 39 & 38 \\
\hline
\end{tabular}

\section{CONCLUSION}

Quality inspection is an important aspect of modern industrial manufacturing. In textile industry production, automate fabric inspection is important to maintain the fabric quality. For a long time, the fabric defect inspection process is still carried out with human visual inspection, and thus, insufficient and costly. Therefore, automatic fabric defect inspection is required to reduce the cost and time waste caused by defects. The development of fully automated web inspection system requires robust and efficient fabric defect detection algorithms. Hence an automated defect detection method and feature extraction technique using GLCM using LabVIEW software is proposed. The fabric image is subjected to preprocessing, wavelet transform. Then the features are extracted for both defect free and defect images. Further these extracted features are given as input to fuzzy system and the rules are formed and classification is completed.Thus the proposed fabric fault inspection using Fuzzy logic implemented with LabVIEW provides better result in identifying the types of faults and classifying them. Textural features plays a major role in determining the accuracy of identification and classification. The above proposed system produces an overall accuracy of $87.5 \%$ by considering the 5 textural features whereas the same proposed system produces an accuracy of 95\% considering 10 textural features.So the classification accuracy is characterized by textural features. 


\section{ACKNOWLEDGEMENT}

I like to express my sincere thanks to my beloved parents and trustworthy friends, for their support towards the successful completion of this paper. I want to express my sincere thanks to my guide Ms.P.Vidhyalakshmi M.Tech, who supported me in all means. Also I would like to express my gratitude to the Department of Science and Technology for their fund.

\section{REFERENCES}

[1] P. Angelov, X. Zhou, F. Klawonn (2007) “Evolving Fuzzy Rule-based Classifiers" IEEE International Conference on Computational Intelligence Applications for Signal and Image Processing, April 1-5.

[2] Bi Mingde,Sun Zhigang(2011) “ Fabric defect detection using undecimated wavelet transform" Information Technology Journal 10(9),1701-1708.

[3] C.-S. Cho, B.-M. Chung and M.-J. Park(2005), "Development of real- time vision-based fabric inspection system", IEEE Trans. Ind. Electron., vol.52, no. 4, pp. 1073-1079

[4] Emmanuel Schmitt, Vincent Bombardier, and Laurent Wendling(2008) "Improving Fuzzy Rule Classifier by Extracting Suitable Features From Capacities With Respect to the Choquet Integral" IEEE transactions on systems, man, and cybernetics-part b: cybernetics, vol. 38 , no. 5 .
[5] Henry Y.T. Ngan , Grantham K.H. Pang , Nelson H.C. Yung (2011) "Automated fabric defect detection-A review" Image and Vision Computing 29, 442-458.

[6] Henry Y.T. Ngan, Grantham K.H. Pana, S.P.Yung, Michael K. $\mathrm{Ng}(2005)$, "Wavelet based methods on patterned fabric defect detection"Pattern Recognition 38 $559-576$.

[7] Kumar A., (2008) "Computer-Vision-Based Fabric Defect Detection: A Survey", IEEE Trans. of Industrial Electronics, vol. 55,No. 1, pp. 348-363.

[8] Li-Wei Han De Xu(2010) "Statistic Learning-based Defect Detection for Twill Fabrics" International Journal of Automation and Computing 7(1), 86-94.

[9] Mahajan P.M., Kolhe S.R. And Patil P.M., (2009) “A review of automatic fabric defect detection techniques" Advances in Computational Research, Volume 1,Issue 2,pp-18-29.

[10]Tzung-Pei Hong, Chai-Ying Lee (1996) "Induction of fuzzy rules and membership functions from training examples"Fuzzy Sets and Systems $8433-47$.

[11] Yu Zhang, Zhaoyang Lu,Jing Li(2010) "Fabric defect classification using radial basis function network" Pattern Recognition Letters 31, 2033-2042

[12] Yanfang Han , Pengfei Shi (2007) "An adaptive levelselecting wavelet transform for texture defect detection" Image and Vision Computing 25, 1239-1248. 